\title{
IJMWT special issue on the European Microwave Week 2008
}

\author{
PETER HOOGEBOOM AND DOMINIQUE SCHREURS
}

Under the auspices of the European Microwave Association (EuMA) the 11th annual European Microwave Week was organized in the Amsterdam RAI Congress Centre, The Netherlands, on October 27-31, 2008. This major event consisted of four conferences, an exhibition, and various side events. The conferences were the 38th European Microwave Conference (EuMC), the 3rd European Microwave Integrated Circuits Conference (EuMIC), the 5th European Radar Conference (EuRAD), and the 1st European Wireless Technology Conference (EuWiT). Note that after recent name changes the year counts for EuMIC and EuWiT were reset. Their actual history is much longer than suggested by the year count.

This 11th edition of the European Microwave Week was a very successful one. We welcomed 1481 participants in the four EuMW conferences. In all, 530 papers were presented in 108 oral sessions, and 195 poster papers were presented in four poster sessions. These were selected from 1082 submitted abstracts.

Although the success of the EuMW carries on in the excellent program book, the conference $\mathrm{CD}$ (this $\mathrm{CD}$ is still available through Horizon House in London, UK), IEEE Xplore, and the Workshop CD (available through peter.hoogeboom@tno.nl), this special issue of the International Journal of Microwave and Wireless Technologies covers the top results from EuMC and EuMIC. This new journal is published by Cambridge University Press in collaboration with EuMA. For EuWiT a special issue of the Journal of Communications published by Academy Publisher will appear in July 2009.

Shortly after these publications, the next edition of the European Microwave Week will take place. We look forward to another inspiring event in Rome, Italy, on September 28- October 2, 2009.

\section{EபMC}

The 2008 version of the EuMC in Amsterdam was organized by Peter Hoogeboom (TNO and TU Delft/IRCTR, The Netherlands, conference chair and EuMW publication chair), Dominique Schreurs (K.U. Leuven, Belgium,
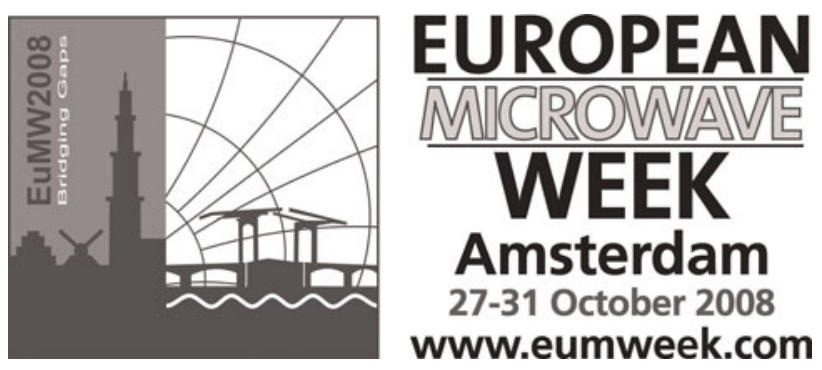

conference co-chair and workshops), and Jan Geralt bij de Vaate (ASTRON, The Netherlands, conference co-chair and TPC chair).

EuMC2008 brought, apart from the traditional sessions in the main conference, topics such as filters, components, antennas, and RFID, and several focused sessions on specially selected topics such as metamaterials, amplifiers, UAV SAR systems, and the SOSTAR-X ground surveillance demonstrator. New conference topics included quality of life and homeland security.

Three prizes were awarded. The EuMC microwave prize (€ 5000) went to Y. Yashchyshyn, Warsaw University of Technology, Poland, for the paper "Extending functionalities of waveguide slot antennas by means of reconfigurable aperture." This paper showed an innovative approach to reconfigurable antennas by the use of switching PIN diodes between patches.

The two EuMC Young Engineers Prizes ( $€ 2000$ each, sponsored by EADS) went to A. Kilian, University Erlangen-Nuremberg, Germany, for the paper "Investigation of the hot embossing technology for low-cost antennas printed on polymer substrates" and to S. Bastioli, University of Perugia, Italy, for the paper "A novel class of compact dual-mode rectangular waveguide filters using square ridge resonators".

Kilian presented a novel metallization technique for polymer substrates to enable the assembly of low-cost microwave antennas. Bastioli described a novel approach in the design of ridge waveguide filters.

\section{EUMIC}

The EuMIC was held for the third time in 2008. The EuMIC conference has evolved from the well-known GAAS 
conference, which was first held in Rome in 1990, where it will return in 2009.

This year's conference was organized by Herbert Zirath (Chalmers, Sweden, conference chair), John Long (Delft University of Technology, The Netherlands, conference co-chair), and Frank van Vliet (TNO and University of Twente, The Netherlands, co-chair and TPC chair). The conference was jointly organized by the EuMA and the GAAS ${ }^{\circledR}$ Association.

Prizes were awarded for the best conference paper and for the best young engineer conference paper. The Young Engineer Prize was awarded to Hiroyuki Takahashi and co-authors for the paper " $120-\mathrm{GHz}$-band low-noise amplifier with 14-ps group-delay variation for 10-Gbit/s data transmission." The combination of real-world specifications at a very challenging communication band set this paper apart from the other nominated papers. The EuMIC Best Paper Award was presented to Erik Öjefors and Ullrich Pfeiffer for their paper "A 94-GHz monolithic front-end for imaging arrays in SiGe:C technology.” A well-determined, long-term strategy, combined with a challenging application and state-of-the-art results were considered laudable. Three GAAS $^{\circledR}$ Association fellowships were awarded to Ph.D. students who showed great promise and interest in microwave electronics: Mrs. Cipriani (University of Rome Tor Vergata), Mr. Abassi (Chalmers University of Technology), and Mr. Yuan (University of Manchester)

After the week we approached the authors of the papers that received the highest reviewer scores as inventoried by the Technical Program committee. The list included the prize winning authors. Following our call, we received positive reactions from most authors and even received several requests from authors who were interested in publishing an extended paper in this first IJMWT special EuMW issue. In the end, an overwhelming 20 extended papers were received. The result is that for this first IJMWT special issue on the EuMW, a double issue was required.

The submissions were reviewed by reviewers who already had evaluated the corresponding conference papers. We wish to acknowledge the following reviewers for their in-depth evaluation of these extended papers: M. Al Ahmad, P. Bertram, J.G. bij de Vaate, S. Bila, V. Boria, M. Camiade, J.-L. Cazaux, Y.-K. Chen, P. Colantonio, F. Danneville,
Y. Deval, G. Di Massa, G. Gerini, S. Harman, J. Hong, I. Huynen, T. Itoh, N. Labbat, F. Lenk, J. Long, G. Magerl, R. Malmqvist, T. Martin-Guerrero, J. Modelski, M. Mrozowski, D. Pasquet, C. Person, M. Prigent, R. Quay, A. Raisanen, R. Ranson, A. Rezazadeh, H. Rogier, J. Saillard, N. Schaeffer, M. Schuessler, R. Snyder, K. Solbach, P. Tasker, M. van Heijningen, F. van Vliet, P. van Zeyl, G. Vandenbosch, V. Vigneras, R. Weigel, and F. Yanovski.

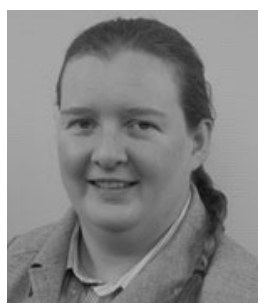

Dominique Schreurs is an associate professor at the Katholieke Universiteit Leuven, Belgium. She received M.Sc. and Ph.D. degrees in electronic engineering from K.U.Leuven. Her main research interests concern the (non-) linear characterization and modeling of active microwave and millimeter-wave devices and circuits, and (non-)linear hybrid and integrated circuit design. She serves on the AdCom of the MTT-S Society and is also vice-chair of the MTT-S TCC. She serves as education chair on the Executive Committee of the ARFTG organization. She was general chair of the 2007 Spring ARFTG Conference and co-chair of the 2008 European Microwave Conference.

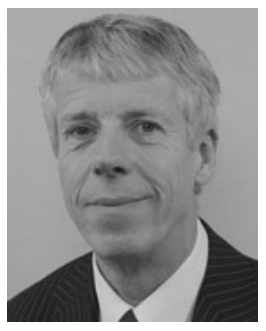

Peter Hoogeboom is a part-time professor in radar earth observation at IRCTR, Delft University of Technology, The Netherlands. He also works as senior advisor for radar at TNO in The Hague. He received his electrical engineering degree from Delft University in 1975 and has worked with TNO since that time. He has extensive experience with radar remote sensing systems and applications. His interest lies in the continuing improvement of performance of radar systems for military and civil applications, by employing new technologies and theories. Currently, he is mostly involved in the development of FMCW SAR, MTI, digital beamforming, and MIMO radar. 